\title{
PESQUISA LINGUÍSTICA NA AMAZÔNIA BRASILEIRA: INTEGRAR PARA FORTALECER
}

\section{LINGUISTIC RESEARCH IN THE BRAZILIAN AMAZON: INTEGRATE TO STRENGTHEN}

\author{
Leandra Ines Seganfredo Santos ${ }^{1}$ \\ Marilucia Barros de Oliveira ${ }^{2}$ \\ Neusa Inês Philippsen ${ }^{3}$ \\ Selma Maria Abdalla Dias Barbosa ${ }^{4}$
}

O recém-criado Grupo de Trabalho intitulado "Estudos Linguísticos na Amazônia Brasileira" (GT ELIAB) foi apresentado à Associação Nacional de Programas de Pós-graduação e Pesquisa em Letras e Linguística - ANPOLL e obteve aprovação do Conselho de Estudos Linguísticos em maio de 2018 durante o XXXIII ENANPOLL (Cuiabá, Mato Grosso, Brasil). O objetivo deste GT é envolver os Programas da área de Linguística localizados na Amazônia brasileira para mostrar que neste espaço amazônico já há uma significativa produção científica que aspira ser implementada com novos resultados e produções. Dentre os resultados que o GT pretende alcançar, destacam-se compartilhar e divulgar a produção científica desenvolvida aqui, com o propósito de cooperar com a pesquisa nacional na área ao mesmo tempo em que disponibiliza resultados de investigações aos interessados nos estudos linguísticos realizados no cenário amazônico.

Palavras-chave: Amazônia brasileira; ANPOLL; GT ELIAB; Programas da área de Linguística.

Abstract: The recently created Working Group entitled "Linguistic Studies in the Brazilian Amazon" (GT ELIAB) was presented to the National Association of Graduate Programs and Research in Letters and Linguistics - ANPOLL and obtained approval from the Council of Linguistic Studies in May 2018 during the XXXIII ENANPOLL (Cuiabá, Mato Grosso, Brazil). The aim of this Working Group (WG) is to involve the Linguistic Programs located in the Brazilian Amazon to show that in this Amazonian space there is already a significant scientific production that aspires to be implemented with new results and productions. Among the results

\footnotetext{
${ }^{1}$ Doutora em Estudos Linguísticos, professora nos Cursos de graduação em Letras e Pedagogia, pós-graduação stricto sensu em Letras (PPGLetras e PROFLETRAS/Sinop). Coordenadora do PPGLetras, Universidade do Estado de Mato Grosso - Sinop, leandraines@ unemat.br

${ }^{2}$ Doutora em Linguística. Professora associada II da Universidade Federal do Pará, Instituto de Letras e Comunicação, com atuação no mestrado e doutorado acadêmicos e mestrado profissional. Investigador visitante do Instituto de Língua Galega-Universidade de Santiago de Compostela (Espanha). Integrante do Comitê Nacional do Atlas Linguístico do Brasil.

${ }^{3}$ Doutora em Letras, professora no Curso de graduação em Letras, pós-graduação stricto sensu em Letras (PPGLetras e PROFLETRAS/Sinop). Vice-Coordenadora do PPGLetras, Universidade do Estado de Mato Grosso - Sinop, neusa.philippsen@unemat.br

${ }^{4}$ Professora Adjunta e docente do Programa de Pós-Graduação em Ensino de Língua e Literatura (PPGL) e PROFLETRAS (Mestrado Profissional) da Universidade Federal do Tocantins, Departamento de Letras. Araguaína. Atua na área de Linguística Aplicada com ênfase em Formação de professores de línguas, selmaabdalla@uft.edu.br
} 
that the WG intends to achieve, we highlight the sharing and dissemination of the scientific production developed here, with the purpose of cooperating with the national research in the area and for those interested in linguistic studies carried out in the Amazon scenario.

Keywords: Brazilian Amazonia; ANPOLL; GT ELIAB; Programs in the area of Linguistics.

\section{Introdução}

Com este texto pretende-se apresentar o mais recente grupo de trabalho aprovado em 2018 pelo Conselho e Assembleia da Associação Nacional de Pós-Graduação e Pesquisa em Letras e Linguística (ANPOLL), denominado "Estudos Linguísticos na Amazônia Brasileira" $(\mathrm{GT} \text { ELIAB })^{5}$.

A iniciativa de propor um GT que envolva os Programas de Pós-Graduação da área de Linguística e Literatura localizados no que tem se denominado Amazônia brasileira, ou Amazônia Legal, justifica-se por esta ser uma vasta região onde o saber científico encontra grandes desafios e como uma ação de valorização da produção teórico-prática da região ${ }^{6}$.

Trata-se de uma área na região da floresta amazônica que envolve nove estados brasileiros: Acre, Amapá, Pará, Amazonas, Rondônia, Roraima e parte dos estados de Mato Grosso, Tocantins e Maranhão. O conceito da Amazônia Legal foi criado pela Lei 1.806 de 06 de janeiro de 1953 com o objetivo de promover e planejar o desenvolvimento da região. Abrange um território de, aproximadamente, $5.217 .423 \mathrm{~km}^{2}$, que corresponde a cerca de $60 \%$ do território brasileiro. Nela, vive uma população indígena habitante com cerca de $55 \%$ de todos os índios brasileiros. Mas, além da população indígena, vive, na Amazônia, um grande número de comunidades quilombolas e povos ribeirinhos, o que intensifica ainda mais seu caráter heterogêneo.

\footnotetext{
${ }^{5}$ Parecer do Conselho de Estudos Linguísticos da ANPOLL de 01 de maio de 2018 e Ata da Assembleia da ANPOLL de 29 de junho de 2018 realizada durante o XXXIII ENANPOLL em Cuiabá, Mato Grosso, Brasil.

${ }^{6} \mathrm{~A}$ instituição do GT é um instrumento, meio de fortalecer a pesquisa na região amazônica. Entende-se que não é o único meio para alcançar esse objetivo, pois, para que isso se concretize, há necessidade, dentre outros, de investimentos na região.
} 
Figura 01 - demonstrativo da área referente à Amazônia Legal

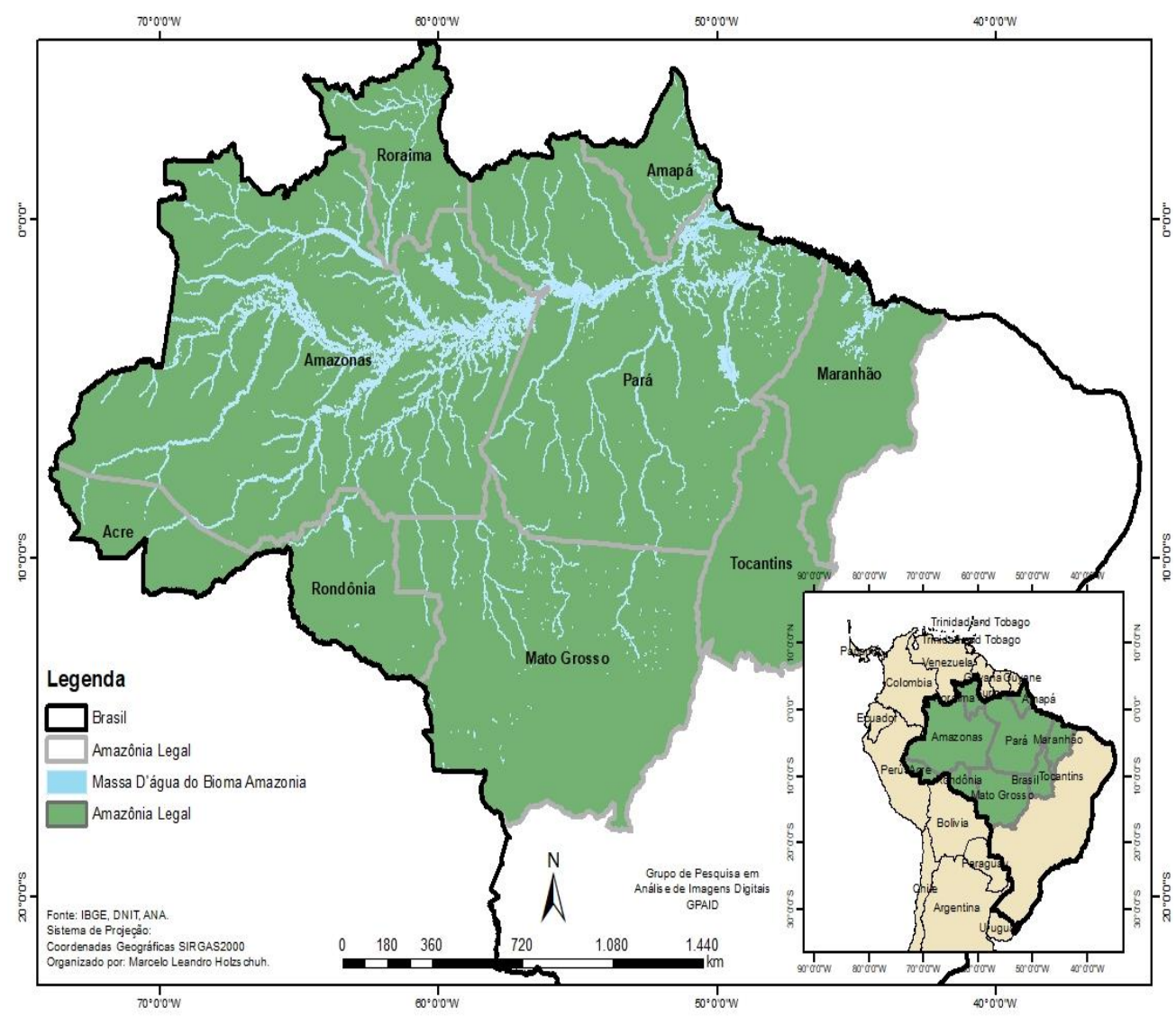

Quando se pensa em Amazônia, geralmente se cogita o elemento indígena, dada a forte presença de várias etnias na região. O elemento africano não é frequentemente pensado como uma etnia que esteve e está presente na Amazônia e, por conseguinte, como o indígena, trouxe e traz contribuições importantes para a cultura e falares regionais amazônicos.

Mesmo assim, pouquíssimos estudos foram realizados no sentido de se discutir a presença e contribuição de línguas africanas ao português falado na região e qual o perfil do português falado em comunidades quilombolas localizadas nessa região, no sentido, inclusive, de apontar que traços dessas línguas ainda resistem no português falado na Amazônia ou, ainda, quais traços linguísticos apresentam as comunidades denominadas remanescentes de quilombos, espaços em que, pretensamente, essas influências e marcas identitárias poderiam ser flagradas e que seriam responsáveis, mas não unicamente, por uma variedade do português que se diferencia das que são encontradas em zonas rurais e urbanas.

Além disso, por sua vez, conforme Heidtmann Neto (2008), a Amazônia Legal pode ser caracterizada atualmente como um lugar urbano, com elevada concentração das populações nas capitais - entretanto, com uma forte territorialidade rural representada por povos tradicionais, 
como seringueiros, ribeirinhos e castanheiros, que lutam pela ocupação de suas terras neste espaço e com sérios problemas de pobreza rural. Nesse sentido, cabe salientar, de acordo com Gama et. al. (2018), que as populações ribeirinhas da Amazônia representam uma mistura de diferentes grupos sociais (indígenas, nordestinos e migrantes de outras regiões). Essas populações vivem em áreas rurais, às margens de rios e lagos na Amazônia brasileira, distribuindo-se em uma área geográfica com cerca de $5.020 .000 \mathrm{~km}^{2}$. No estado do Amazonas, a população estimada, no ano de 2010, foi de 3.483 .985 habitantes e 728.495 (20,1\%) viviam em área rural.

Dentre as principais atividades econômicas destacam-se o extrativismo vegetal e mineral, a agricultura, a pesca, a atividade industrial (principalmente na Zona Franca de Manaus), o comércio e serviços (nas cidades de porte médio e capitais dos estados).

É neste espaço plural que os Programas de Linguística e Literatura têm se constituído como espaços profícuos que visam a compreensão da linguagem em suas manifestações sociais, culturais e históricas no contexto da Amazônia. Caracterizam-se, também, por contribuírem no aprofundamento das investigações referentes às diversas manifestações linguísticas nos contextos social e cultural. Alinham-se a esses objetivos, a criação de mecanismos para intensificar a produção científica articulada e produzida pelos pesquisadores, a partir dos conceitos fundantes das teorias, linhas de pesquisa, projetos e grupos de pesquisa que os formam. Ademais, espera-se integrar e fortalecer os Programas em busca de melhorias nos índices de avaliações quadrienais.

\section{Estudos Linguísticos na Amazônia Brasileira (GT ELIAB): a proposta e os desafios}

As pesquisas desenvolvidas no âmbito do grupo devem privilegiar aspectos ligados à Amazônia, mas isso não significa que essa ação será solitária e que não esteja em interação com pesquisas realizadas no Brasil e fora dele. Os membros do grupo, em geral, têm estabelecido interação com outros grupos de pesquisa de universidades brasileiras e do exterior. Essa interação permitirá comparabilidade entre resultados das diferentes pesquisas, bem como se caracterizará o elo para pesquisas que são específicas, mas não isoladas.

Cabe ressaltar que a intempestiva implantação de Programas de Pós-Graduação em algumas capitais da região amazônica implicou um desnivelamento da produção acadêmica entre as regiões do Brasil. Por sua vez, isso está sendo superado pela implantação desses 
Programas, o que significa mais pessoal qualificado para o desenvolvimento de pesquisas na região.

A presente ação se caracteriza como contribuição para o desenvolvimento da pesquisa na região que trará impacto efetivo para as pesquisas no Brasil. Não raro alguns pesquisadores brasileiros buscam algumas evidências ou comparações que, em tese, poderiam ser efetivadas se houvesse resultados de pesquisas desenvolvidas na Amazônia. No mais, cabe reforçar a diversidade exuberante de línguas e culturas na região que precisam ser descritas, documentadas e analisadas.

Na tabela que segue, estão elencados os Programas na área Linguística e Literatura na região que compreende a Amazônia brasileira. Vale salientar que boa parte destes Programas é bastante jovem e, inclusive, está em processo de filiação à ANPOLL. No momento de proposição de criação do GT, foram envolvidos docentes de sete instituições de ensino superior. Entretanto, nosso objetivo é, com o passar do tempo, agregar pesquisadores de todos os Programas da região e de professores de Programas que não são da região, mas se ocupam de pesquisa sobre a Amazônia.

Quadro 1 - Programas na área de Linguística e Literatura nos estados que compõem a Amazônia brasileira

\begin{tabular}{|c|c|c|c|}
\hline Estados & IES & Nome do Programa & $\begin{array}{l}\text { Ano início } \\
\text { (Mestrado/ } \\
\text { Doutorado) }\end{array}$ \\
\hline \multirow[t]{2}{*}{ Acre (AC) } & \multirow[t]{2}{*}{ UFAC } & Letras: Linguagem e Identidade & 2010 \\
\hline & & PROFLETRAS & 2013 \\
\hline Amapá (AP) & Não possui Programa & --- & --- \\
\hline \multirow[t]{2}{*}{ Amazonas (AM) } & UEA & Letras e Artes & 2015 \\
\hline & UFAM & Letras & 2010 \\
\hline Maranhão (MA) & UEMA & Letras & 2015 \\
\hline \multirow{5}{*}{$\begin{array}{ll}\text { Mato } & \text { Grosso } \\
(\mathrm{MT}) & \end{array}$} & \multirow[t]{2}{*}{ UNEMAT/Sinop } & Letras & 2016 \\
\hline & & PROFLETRAS & 2013 \\
\hline & \multirow[t]{2}{*}{ UNEMAT/Cáceres } & PROFLETRAS & 2013 \\
\hline & & Linguística & $2010 / 2016^{7}$ \\
\hline & UFMT/Cuiabá & Estudos de Linguagem & $2003 / 2015$ \\
\hline \multirow[t]{6}{*}{ Pará (PA) } & \multirow{3}{*}{ UFPA } & Letras: linguística e teoria literária & $1997 / 2013$ \\
\hline & & Linguagens e saberes da Amazônia & 2011 \\
\hline & & PROFLETRAS (Belém) & 2013 \\
\hline & UFOPA & PROFLETRAS (Santarém) & 2013 \\
\hline & \multirow[t]{2}{*}{ UNIFESSPA } & Letras & 2017 \\
\hline & & PROFLETRAS/Marabá & 2013 \\
\hline Rondônia (RO) & UNIR & Letras & 2010 \\
\hline Roraima (RR) & UFRR & Letras & 2010 \\
\hline \multirow[t]{3}{*}{ Tocantins (TO) } & UFT/Araguaína & Ensino de Língua e Literatura & 2010 \\
\hline & UFT/Araguaína & PROFLETRAS & 2013 \\
\hline & UFT/Palmas & Letras & 2015 \\
\hline
\end{tabular}

\footnotetext{
${ }^{77}$ A primeira data refere-se ao ano de início do Curso de Mestrado e a segunda ao Curso de Doutorado.
} 
Fonte: sítios eletrônicos da Plataforma Sucupira e da ANPOLL (março de 2018).

Como se pode notar, ainda há, na região, universidades que não têm Programa ou curso de pós-graduação na área. A formação deste GT tem também como meta o fortalecimento dos grupos de pesquisas no sentido de colaborar com essas instituições, a fim de que tenham implantados Programas de pós-graduação. Essa meta vai muito além de um olhar apenas sobre questões acadêmicas. Ela apresenta-se como uma atuação que tem impacto social sobre a região, visto que dará oportunidade a muitos moradores da região de poderem cursar mestrado e/ou doutorado sem terem que se deslocar para outras universidades ou regiões, o que, embora apresente pontos positivos, por conta da interação com outras culturas acadêmicas e da especialidade que é desejada pelos que querem cursar pós-graduação, muitas vezes é inviável dado os custos que isso implica.

O quadro 1 também revela que alguns Programas já apresentam mais de um curso, o que é um ponto muito positivo para a região. Mas isso ainda se apresenta de forma muito localizada e precisa ser expandido. Destarte, uma das metas do grupo é colaborar para a instituição de cursos de mestrado e expandir os cursos de doutorado para outras universidades da região.

Quadro 2 - Programas, cursos e linhas de pesquisa em Estudos Linguísticos

\begin{tabular}{|c|c|c|c|c|}
\hline IES & $\begin{array}{l}\text { Nome do } \\
\text { Programa }\end{array}$ & Curso(s) & $\begin{array}{c}\text { Área(s) de } \\
\text { Concentração }\end{array}$ & Linha(s) de Pesquisa \\
\hline \multirow[t]{2}{*}{ UFAC } & $\begin{array}{l}\text { Letras: } \\
\text { Linguagem e } \\
\text { Identidade }\end{array}$ & $\begin{array}{l}\text { Mestrado } \\
\text { Acadêmico }\end{array}$ & $\begin{array}{l}\text { Estudos de } \\
\text { linguagem e } \\
\text { cultura regional }\end{array}$ & $\begin{array}{l}\text { 1. Língua e Cultura Regional } \\
\text { 2. Literatura, Artes e Cultura Regional }\end{array}$ \\
\hline & PROFLETRAS & $\begin{array}{l}\text { Mestrado } \\
\text { Profissional }\end{array}$ & $\begin{array}{l}\text { Linguagens e } \\
\text { Letramentos }\end{array}$ & $\begin{array}{l}\text { 1. Teorias da Linguagem e Ensino } \\
\text { 2. Leitura e Produção Textual: } \\
\text { diversidade social e práticas } \\
\text { docentes }\end{array}$ \\
\hline UEA & Letras e Artes & $\begin{array}{l}\text { Mestrado } \\
\text { Profissional }\end{array}$ & $\begin{array}{l}\text { Representação e } \\
\text { interpretação } \\
\text { artística, literária e } \\
\text { linguística }\end{array}$ & $\begin{array}{l}\text { 1. Representação e Interpretação } \\
\text { Artística } \\
\text { 2. Representação e Interpretação } \\
\text { Literária } \\
\text { 3. Representação e Interpretação } \\
\text { Etnolinguística }\end{array}$ \\
\hline UFAM & Letras & $\begin{array}{l}\text { Mestrado } \\
\text { Acadêmico }\end{array}$ & $\begin{array}{l}\text { 1. Estudos } \\
\text { literários } \\
\text { 2. Estudos da } \\
\text { linguagem }\end{array}$ & $\begin{array}{l}\text { 1. Literatura, cultura e } \\
\text { transdisciplinaridade } \\
\text { 2. Literatura e outras linguagens } \\
\text { 3. Sociolinguística / Dialetologia } \\
\text { 4. Linguística Aplicada } \\
\text { 5. Estudos dos discursos }\end{array}$ \\
\hline UFMA & Letras & $\begin{array}{l}\text { Mestrado } \\
\text { Acadêmico }\end{array}$ & $\begin{array}{l}\text { Estudos da } \\
\text { Linguagem }\end{array}$ & $\begin{array}{l}\text { 1. Descrição e Análise do Português } \\
\text { Brasileiro } \\
\text { 2. Discurso, Literatura e } \\
\text { Memória }\end{array}$ \\
\hline
\end{tabular}




\begin{tabular}{|c|c|c|c|c|}
\hline \multirow[t]{2}{*}{$\begin{array}{l}\text { UNEMAT/ } \\
\text { Sinop }\end{array}$} & Letras & $\begin{array}{l}\text { Mestrado } \\
\text { Acadêmico }\end{array}$ & $\begin{array}{l}\text { Estudos } \\
\text { Linguísticos e } \\
\text { Literários }\end{array}$ & $\begin{array}{l}\text { 1. Estudos Linguísticos } \\
\text { 2. Estudos Literários }\end{array}$ \\
\hline & PROFLETRAS & $\begin{array}{l}\text { Mestrado } \\
\text { Profissional }\end{array}$ & $\begin{array}{l}\text { Linguagens e } \\
\text { Letramentos }\end{array}$ & $\begin{array}{l}\text { 1. Teorias da Linguagem e Ensino; } \\
\text { 2. Leitura e Produção Textual: } \\
\text { diversidade social e práticas } \\
\text { docentes }\end{array}$ \\
\hline \multirow[t]{2}{*}{$\begin{array}{l}\text { UNEMAT/ } \\
\text { Cáceres }\end{array}$} & PROFLETRAS & $\begin{array}{l}\text { Mestrado } \\
\text { Profissional }\end{array}$ & $\begin{array}{l}\text { Linguagens e } \\
\text { Letramentos }\end{array}$ & $\begin{array}{l}\text { 1. Teorias da Linguagem e Ensino; } \\
\text { 2. Leitura e Produção Textual: } \\
\text { diversidade social e práticas } \\
\text { docentes }\end{array}$ \\
\hline & Linguística & $\begin{array}{l}\text { Mestrado e } \\
\text { Doutorado } \\
\text { Acadêmico }\end{array}$ & $\begin{array}{l}\text { Estudo de } \\
\text { processos } \\
\text { linguísticos }\end{array}$ & $\begin{array}{l}\text { 1. Estudo de processos discursivos } \\
\text { 2. Estudo de processos de significação } \\
\text { 3. Estudo de processos de variação e } \\
\text { mudança } \\
\text { 4. Estudo de processos de práticas } \\
\text { sociais da linguagem } \\
\text { 5. Estudo de processos descritivos, de } \\
\text { análise e de documentação de línguas } \\
\text { indígenas }\end{array}$ \\
\hline $\begin{array}{l}\text { UFMT/ } \\
\text { Cuiabá }\end{array}$ & $\begin{array}{l}\text { Estudos de } \\
\text { Linguagem }\end{array}$ & $\begin{array}{l}\text { Mestrado e } \\
\text { Doutorado } \\
\text { Acadêmico }\end{array}$ & $\begin{array}{l}\text { 1. Estudos } \\
\text { Linguísticos } \\
\text { 2. Estudos } \\
\text { Literários }\end{array}$ & $\begin{array}{l}\text { 1. Paradigmas de Ensino de Línguas } \\
\text { 2. Práticas textuais e discursivas: } \\
\text { múltiplas abordagens } \\
\text { 3. Literatura e Outras Artes, } \\
\text { Memórias e Fronteiras } \\
\text { 4. Literatura e Realidade Social }\end{array}$ \\
\hline \multirow[t]{3}{*}{ UFPA } & $\begin{array}{l}\text { Letras: } \\
\text { linguística e } \\
\text { teoria literária }\end{array}$ & $\begin{array}{l}\text { Mestrado e } \\
\text { Doutorado } \\
\text { Acadêmico }\end{array}$ & $\begin{array}{l}\text { 1. Estudos } \\
\text { Linguísticos } \\
\text { 2. Estudos } \\
\text { Literários }\end{array}$ & $\begin{array}{l}\text { 1. Literatura: interpretação, } \\
\text { circulação e recepção } \\
\text { 2. Literatura, Memórias e Identidades } \\
\text { 3. Análise, Descrição e } \\
\text { Documentação das Línguas Naturais } \\
\text { 4. Ensino-aprendizagem de Línguas e } \\
\text { Culturas: modelos e ações }\end{array}$ \\
\hline & $\begin{array}{l}\text { Linguagens e } \\
\text { saberes da } \\
\text { Amazônia } \\
\end{array}$ & $\begin{array}{l}\text { Mestrado } \\
\text { Acadêmico }\end{array}$ & $\begin{array}{l}\text { Linguagens e } \\
\text { Saberes }\end{array}$ & $\begin{array}{l}\text { 1. Leitura e Tradução Cultural } \\
\text { 2. Memórias e Saberes Interculturais } \\
\text { 3. Educação, Cultura e Sociedade }\end{array}$ \\
\hline & $\begin{array}{l}\text { PROFLETRAS } \\
\text { (Belém) }\end{array}$ & $\begin{array}{l}\text { Mestrado } \\
\text { Profissional }\end{array}$ & $\begin{array}{l}\text { Linguagens e } \\
\text { Letramentos }\end{array}$ & $\begin{array}{l}\text { 1. Teorias da Linguagem e Ensino; } \\
\text { 2. Leitura e Produção Textual: } \\
\text { diversidade social e práticas } \\
\text { docentes }\end{array}$ \\
\hline UFOPA & $\begin{array}{l}\text { PROFLETRAS } \\
\text { (Santarém) }\end{array}$ & $\begin{array}{l}\text { Mestrado } \\
\text { Profissional }\end{array}$ & $\begin{array}{l}\text { Linguagens e } \\
\text { Letramentos }\end{array}$ & $\begin{array}{l}\text { 1. Teorias da Linguagem e Ensino; } \\
\text { 2. Leitura e Produção Textual: } \\
\text { diversidade social e práticas } \\
\text { docentes }\end{array}$ \\
\hline \multirow[t]{2}{*}{ UNIFESSPA } & Letras & $\begin{array}{l}\text { Mestrado } \\
\text { Acadêmico }\end{array}$ & $\begin{array}{l}\text { Linguagem e } \\
\text { Sociedade }\end{array}$ & $\begin{array}{l}\text { 1. Estudos Comparados, Culturais e } \\
\text { Interdisciplinares em Literatura } \\
\text { 2. Linguagem, Discurso e Sociedade }\end{array}$ \\
\hline & $\begin{array}{l}\text { PROFLETRAS } \\
\text { (Marabá) }\end{array}$ & $\begin{array}{l}\text { Mestrado } \\
\text { Profissional }\end{array}$ & $\begin{array}{l}\text { Linguagens e } \\
\text { Letramentos }\end{array}$ & $\begin{array}{l}\text { 1. Teorias da Linguagem e Ensino; } \\
\text { 2. Leitura e Produção Textual: } \\
\text { diversidade social e práticas } \\
\text { docentes }\end{array}$ \\
\hline UNIR & Letras & $\begin{array}{l}\text { Mestrado } \\
\text { Acadêmico }\end{array}$ & $\begin{array}{l}\text { Línguas, } \\
\text { Linguagens e } \\
\text { Culturas } \\
\text { Amazônicas }\end{array}$ & $\begin{array}{l}\text { 1. Estudos descritivos e aplicados de } \\
\text { Línguas e Linguagens } \\
\text { 2. Estudos de Diversidade Cultural }\end{array}$ \\
\hline UFRR & Letras & $\begin{array}{l}\text { Mestrado } \\
\text { Acadêmico }\end{array}$ & $\begin{array}{l}\text { Estudos de } \\
\text { Linguagem e } \\
\text { Cultura Regional }\end{array}$ & $\begin{array}{l}\text { 1. Língua e Cultura Regional } \\
\text { 2. Literatura, Artes e Cultura Regional }\end{array}$ \\
\hline
\end{tabular}




\begin{tabular}{|c|l|l|l|l|}
\hline $\begin{array}{c}\text { UFT/ } \\
\text { Araguaína }\end{array}$ & $\begin{array}{l}\text { Ensino de } \\
\text { Língua e } \\
\text { Literatura }\end{array}$ & $\begin{array}{l}\text { Mestrado e } \\
\text { Doutorado } \\
\text { Acadêmico }\end{array}$ & $\begin{array}{l}\text { Ensino e } \\
\text { formação de } \\
\text { professor de } \\
\text { língua e de } \\
\text { literatura }\end{array}$ & $\begin{array}{l}\text { 1. Linguagem, educação e } \\
\text { diversidade cultural } \\
\text { 2. Literatura, memória e identidade } \\
\text { cultural em contextos de formação } \\
\text { 3. Práticas discursivas em contextos } \\
\text { de formação } \\
\text { 4. Teoria e análise linguística em } \\
\text { contextos de formação }\end{array}$ \\
\hline UFT/ & PROFLETRAS & $\begin{array}{l}\text { Mestrado } \\
\text { Profissional }\end{array}$ & $\begin{array}{l}\text { Linguagens e } \\
\text { Letramentos }\end{array}$ & $\begin{array}{l}\text { 1. Teorias da Linguagem e Ensino; } \\
\text { 2. Leitura e Produção Textual: } \\
\text { diversidade social e práticas } \\
\text { docentes }\end{array}$ \\
\hline UFT/Palmas & Letras & $\begin{array}{l}\text { Mestrado } \\
\text { Acadêmico }\end{array}$ & $\begin{array}{l}\text { Estudos } \\
\text { Linguísticos } \\
\text { Estudos Literários }\end{array}$ & $\begin{array}{l}\text { 1. Abordagens de Análise Linguística } \\
\text { 2. Linguística Aplicada } \\
\text { 3. Literatura, História e Imaginário } \\
\text { 4. Teoria e Crítica Literária } \\
\text { 5. Literatura Comparada }\end{array}$ \\
\hline
\end{tabular}

Fonte: sítios eletrônicos da Plataforma Sucupira e da ANPOLL (agosto de 2018).

O GT foi inicialmente articulado por duas professoras-pesquisadoras da UNEMAT/Sinop que se dispuseram a fazer uma pesquisa preliminar dos Programas e estabelecer os primeiros contatos com os coordenadores. Algumas respostas foram rápidas e sinalizavam positivamente, indicando possíveis docentes interessados. De alguns Programas, entretanto, não se obtiveram respostas, outros, por sua vez, respondiam parabenizando pela iniciativa e declinando do convite por já participarem de outro GT ou alegando excesso de atividades que prejudicariam possível participação no grupo.

Em um segundo momento, a contato foi feito diretamente com docentes, cujos endereços eletrônicos foram obtidos nas páginas dos respectivos Programas dos quais fazem parte. Cabe ressaltar que treze docentes compõem a equipe fundadora do GT, sob a coordenação das pesquisadoras Leandra Ines Seganfredo Santos (coordenadora) e Neusa Inês Philippsen (vice-coordenadora), da UNEMAT/Sinop.

Quadro 3 - Componentes do GT e Instituições de Ensino Superior representadas

\begin{tabular}{|c|l|l|c|c|}
\hline & \multicolumn{1}{|c|}{ Docente } & \multicolumn{1}{|c|}{ Link currículo } & IES & Programa \\
\hline 1. & Cristinne Leus Tomé & http://lattes.cnpq.br/5252249925535846 & $\begin{array}{c}\text { UNEMAT/ } \\
\text { Sinop }\end{array}$ & PPG Letras \\
\hline 2. & $\begin{array}{l}\text { Emerson Carvalho de } \\
\text { Souza }\end{array}$ & http://lattes.cnpq.br/2507924242370719 & UFRR & PPG Letras \\
\hline 3. & José Leonildo Lima & http://lattes.cnpq.br/7205996134648701 & $\begin{array}{l}\text { UNEMAT/ } \\
\text { Nova Mutum }\end{array}$ & $\begin{array}{c}\text { PROFLETRAS } \\
\text { /Cáceres }\end{array}$ \\
\hline 4. & $\begin{array}{l}\text { Leandra Ines } \\
\text { Seganfredo Santos }\end{array}$ & http://lattes.cnpq.br/4914933128365763 & $\begin{array}{c}\text { UNEMAT/ } \\
\text { Sinop }\end{array}$ & $\begin{array}{c}\text { PPG Letras } \\
\text { PROFLETRAS } \\
\text { /Sinop }\end{array}$ \\
\hline 5. & $\begin{array}{l}\text { Leonard Christy Souza } \\
\text { Costa }\end{array}$ & http://lattes.cnpq.br/6253814174927313 & UFAM & PPG Letras \\
\hline
\end{tabular}




\begin{tabular}{|c|c|c|c|c|}
\hline 6. & $\begin{array}{l}\text { Maria Luiza Cruz } \\
\text { Cardoso }\end{array}$ & http://lattes.cnpq.br/0121166273814163 & UFAM & PPG Letras \\
\hline 7. & $\begin{array}{l}\text { Marília Lima Pimentel } \\
\text { Cotinguiba }\end{array}$ & http://lattes.cnpq.br/2889057943194849 & UNIR & PPG Letras \\
\hline 8. & $\begin{array}{l}\text { Marilucia Barros de } \\
\text { Oliveira }\end{array}$ & http://lattes.cnpq.br/9728768970430501 & UFPA & PPG Letras \\
\hline 9. & Neusa Inês Philippsen & http://lattes.cnpq.br/6576939578371604 & $\begin{array}{l}\text { UNEMAT/ } \\
\text { Sinop }\end{array}$ & $\begin{array}{c}\text { PPG Letras } \\
\text { PROFLETRAS } \\
\text { /Sinop }\end{array}$ \\
\hline 10. & $\begin{array}{l}\text { Selma Maria Abdalla } \\
\text { Dias Barbosa }\end{array}$ & http://lattes.cnpq.br/3885079112744847 & $\begin{array}{c}\text { UFT/ } \\
\text { Araguaína }\end{array}$ & $\begin{array}{c}\text { PPGL Ensino } \\
\text { de Língua e } \\
\text { Literatura }\end{array}$ \\
\hline 11. & $\begin{array}{l}\text { Silvana Andrade } \\
\text { Martins }\end{array}$ & http://lattes.cnpq.br/0455709808630889 & $\begin{array}{l}\text { UEA/ } \\
\text { Manaus }\end{array}$ & PPGLA \\
\hline 12. & $\begin{array}{l}\text { Wellington Pedrosa } \\
\text { Quintino }\end{array}$ & http://lattes.cnpq.br/7719301265986482 & $\begin{array}{l}\text { UNEMAT/ } \\
\text { Cáceres }\end{array}$ & $\begin{array}{c}\text { PPG } \\
\text { Linguística }\end{array}$ \\
\hline 13. & $\begin{array}{l}\text { Zoraide dos Anjos } \\
\text { Gonçalves da Silva } \\
\text { Vieira }\end{array}$ & http://lattes.cnpq.br/2820915152185843 & UFRR & PPG Letras \\
\hline
\end{tabular}

Fonte: Elaboração das autoras, 2018.

Alguns desses pesquisadores ainda não eram ligados a nenhum grupo da ANPOLL; outros desistiram da participação em outros GTs por considerarem a necessidade de fortalecer as atividades de pesquisa na região. Desta forma, este quadro inicial será ampliado com a chegada de novos membros e adesão de novos Programas.

Na perspectiva da produtividade e da contribuição social do GT, os pesquisadores que compõem o quadro inicial preocupam-se com os fenômenos relacionados à formação docente, ao ensino das línguas e à valorização da diversidade linguística e cultural. Nesse sentido, o leque das teorias linguísticas é amplo, abarcando uma pluralidade significativa de perspectivas que tratam dos enfoques diversificados de tais fenômenos. Sendo assim, preocupam-se com fenômenos relacionados à formação de professores capacitados aos temas e fatores linguísticos e socioculturais peculiares à região amazônica e ao ensino das línguas, contemplando a diversidade e interculturalidade dos povos que vivem nesta região.

Quadro 4 - Componentes do GT e Instituições de Ensino Superior representadas

\begin{tabular}{|c|l|l|l|l|}
\hline \multicolumn{2}{|c|}{ Docente } & \multicolumn{1}{|c|}{ Atuação } & \multicolumn{1}{|c|}{$\begin{array}{c}\text { Tema(s) de interesse(s) } \\
\text { de pesquisa atual }\end{array}$} & $\begin{array}{l}\text { Referência bibliográfica } \\
\text { básica ligada à pesquisa } \\
\text { desenvolvida no âmbito } \\
\text { do GT }\end{array}$ \\
\hline 1. & $\begin{array}{l}\text { Cristinne Leus } \\
\text { Tomé }\end{array}$ & Análise do Discurso & $\begin{array}{l}\text { História e sustentabilidade } \\
\text { na Amazônia }\end{array}$ & $\begin{array}{l}\text { Tomé, 2009; } \\
\text { Tomé e Rohden, 2017; } \\
\text { Tomé e Rodrigues, 2018. }\end{array}$ \\
\hline 2. & $\begin{array}{l}\text { Emerson Carvalho } \\
\text { de Souza }\end{array}$ & $\begin{array}{l}\text { Fonologia } \\
\text { Descrição e } \\
\text { documentação de } \\
\text { línguas indígenas }\end{array}$ & $\begin{array}{l}\text { Variação fonológica e } \\
\text { Português como Língua de } \\
\text { interculturalidade em } \\
\text { contexto indígena. }\end{array}$ & Souza, 2012. \\
\hline
\end{tabular}




\begin{tabular}{|c|c|c|c|c|}
\hline 3. & José Leonildo Lima & $\begin{array}{l}\text { Sociolinguística; } \\
\text { Dialetologia e } \\
\text { Geografia } \\
\text { Linguística }\end{array}$ & $\begin{array}{l}\text { Atlas linguístico, } \\
\text { vocabulário regional, } \\
\text { variação e mudança } \\
\text { linguística, gênero } \\
\text { gramatical. }\end{array}$ & $\begin{array}{l}\text { Oliveira e Lima, 2014; } \\
\text { Lima, 2018; } \\
\text { Philippsen e Lima, } 2018 .\end{array}$ \\
\hline 4. & $\begin{array}{l}\text { Leandra Ines } \\
\text { Seganfredo Santos }\end{array}$ & $\begin{array}{l}\text { Linguística } \\
\text { Aplicada }\end{array}$ & $\begin{array}{l}\text { Formação de professores } \\
\text { de línguas, ensino e } \\
\text { aprendizagem de línguas e } \\
\text { multiletramentos }\end{array}$ & $\begin{array}{l}\text { Santos e Sobrinho, 2015; } \\
\text { Santos, 2016; } \\
\text { Lima e Santos, } 2017 .\end{array}$ \\
\hline 5. & $\begin{array}{l}\text { Leonard Christy } \\
\text { Souza Costa }\end{array}$ & $\begin{array}{l}\text { Análise do Discurso } \\
\text { e Linguística } \\
\text { Aplicada }\end{array}$ & $\begin{array}{l}\text { Análise do discurso } \\
\text { francesa, discurso político, } \\
\text { discurso religioso, discurso } \\
\text { jurídico, letramento crítico } \\
\text { e letramento prisional. }\end{array}$ & $\begin{array}{l}\text { Costa, 2017; } \\
\text { Silveira, Aguiar e Costa, } \\
\text { 2017; } \\
\text { Silveira, Silva e Costa, } \\
2017 .\end{array}$ \\
\hline 6. & $\begin{array}{l}\text { Maria Luiza Cruz } \\
\text { Cardoso }\end{array}$ & $\begin{array}{l}\text { Dialetologia e } \\
\text { Sociolinguística }\end{array}$ & $\begin{array}{l}\text { Conhecimento do falar do } \\
\text { Amazonas, nos níveis } \\
\text { fonético-fonológico, } \\
\text { morfossintático e lexical. }\end{array}$ & $\begin{array}{l}\text { Cruz-Cardoso, 2017; } \\
\text { Cruz-Cardoso, Maia e } \\
\text { Martins, } 2017 .\end{array}$ \\
\hline 7. & $\begin{array}{l}\text { Marília Lima } \\
\text { Pimentel } \\
\text { Cotinguiba }\end{array}$ & $\begin{array}{l}\text { Linguística } \\
\text { Aplicada }\end{array}$ & $\begin{array}{l}\text { Ensino de Língua } \\
\text { Portuguesa como língua de } \\
\text { acolhimento para } \\
\text { imigrantes }\end{array}$ & $\begin{array}{l}\text { Cotinguiba-Pimentel, } \\
\text { Santos e Assis, 2015; } \\
\text { Cotinguiba-Pimentel, } \\
\text { Cotinguiba e Ribeiro, } \\
\text { 2016; } \\
\text { Cotinguiba-Pimentel, } \\
\text { Cotinguiba e Andretta, } \\
2018 \text {. }\end{array}$ \\
\hline 8. & $\begin{array}{l}\text { Marilucia Barros de } \\
\text { Oliveira }\end{array}$ & $\begin{array}{l}\text { Sociolinguística, } \\
\text { Dialetologia, } \\
\text { Fonética e } \\
\text { Fonologia }\end{array}$ & $\begin{array}{l}\text { Atlas Linguísticos; } \\
\text { descrição e diversidade } \\
\text { linguísticas em } \\
\text { comunidades } \\
\text { afrodescendentes e } \\
\text { indígenas; palatalização. }\end{array}$ & $\begin{array}{l}\text { Oliveira, 2010, 2014, } \\
2017 .\end{array}$ \\
\hline 9. & $\begin{array}{l}\text { Neusa Inês } \\
\text { Philippsen }\end{array}$ & $\begin{array}{l}\text { Dialetologia } \\
\text { Sociolinguística e } \\
\text { Linguística } \\
\text { Aplicada }\end{array}$ & $\begin{array}{l}\text { Atlas linguístico, } \\
\text { Variedades e diversidades } \\
\text { linguísticas, } \\
\text { Estudos Semântico- } \\
\text { Lexicais e } \\
\text { Morfossintáticos, } \\
\text { Processos de ensino- } \\
\text { aprendizagens }\end{array}$ & $\begin{array}{l}\text { Philippsen, 2017; } \\
\text { Oliveira e Philippsen, } \\
\text { 2017; } \\
\text { Philippsen e Lima, 2018; } \\
\text { Tavares de Barros, } \\
\text { Machado, Heidmann e } \\
\text { Philippsen, 2018. }\end{array}$ \\
\hline 10 . & $\begin{array}{l}\text { Selma Maria } \\
\text { Abdalla Dias } \\
\text { Barbosa }\end{array}$ & $\begin{array}{l}\text { Linguística } \\
\text { Aplicada }\end{array}$ & $\begin{array}{l}\text { Identidade, crenças e } \\
\text { emoções do professor de } \\
\text { línguas, formação de } \\
\text { professores e tecnologia de } \\
\text { informação e comunicação } \\
\text { no ensino e aprendizagem } \\
\text { de línguas }\end{array}$ & $\begin{array}{l}\text { Bedran e Barbosa 2016; } \\
\text { 2017; } \\
\text { Barbosa, } 2016 .\end{array}$ \\
\hline 11. & $\begin{array}{l}\text { Silvana Andrade } \\
\text { Martins }\end{array}$ & $\begin{array}{l}\text { Sociolinguística e } \\
\text { Transculturalidade, } \\
\text { linguagem e } \\
\text { educação }\end{array}$ & $\begin{array}{l}\text { Educação Escolar Indígena } \\
\text { e Descrição do Português } \\
\text { Amazonense (aspectos } \\
\text { morfossintáticos) }\end{array}$ & $\begin{array}{l}\text { Martins e Martins, 2014; } \\
\text { Martins e Lima, 2017, } \\
2018 .\end{array}$ \\
\hline 12. & $\begin{array}{l}\text { Wellington Pedrosa } \\
\text { Quintino }\end{array}$ & $\begin{array}{l}\text { Fonética, fonologia, } \\
\text { descrição e } \\
\text { documentação de } \\
\text { línguas indígenas }\end{array}$ & $\begin{array}{l}\text { Descrição e documentação } \\
\text { da língua indígena } \\
\text { Nambikwara }\end{array}$ & $\begin{array}{l}\text { Quintino, 2012; } \\
\text { Mori, Cruz e Quintino, } \\
2017 .\end{array}$ \\
\hline
\end{tabular}




\begin{tabular}{|c|c|c|c|c|}
\hline 13. & $\begin{array}{l}\text { Zoraide dos Anjos } \\
\text { Gonçalves da Silva } \\
\text { Vieira }\end{array}$ & $\begin{array}{l}\text { Teoria e Análise } \\
\text { Linguística; } \\
\text { Fonologia; } \\
\text { Morfossintaxe de } \\
\text { línguas naturais }\end{array}$ & $\begin{array}{l}\text { Descrição de línguas } \\
\text { indígenas e/ou minoritárias } \\
\text { na perspectiva funcional- } \\
\text { tipológica. } \\
\text { Línguas em contato. } \\
\text { Ensino bilíngue. }\end{array}$ & $\begin{array}{l}\text { Anjos, 2011; 2012; } \\
\text { Queixalós e Anjos, } \\
2006 .\end{array}$ \\
\hline
\end{tabular}

Fonte: Elaboração das autoras, 2018.

As atividades do GT estão, prioritariamente, vinculadas a eventos representativos da área de Linguística, com destaque para as subáreas relacionadas à Linguística Aplicada, Análise do Discurso, Descrição de Línguas, Sociolinguística, Dialetologia e a linguagem em seu uso na sociedade em diversos contextos sociais, históricos, políticos e culturais, e a eventos científicos já desenvolvidos por seus integrantes, em articulação com Grupos e/ou Projetos de Pesquisa em andamento junto a diversos Programas de Pós-Graduação (nas suas respectivas instituições) e articulados com orientações de graduação/pós-graduação e veículos de publicação. Aproveitando as ocasiões desses eventos, ocorrerão periodicamente reuniões do Grupo, destinadas a fomentar ideias, discutir resultados de pesquisa, articular e integrar investigações individuais. Somam-se, também, reuniões à distância por webconferência para discussões e planejamentos.

Como produto da participação nessas atividades, haverá publicações em anais de eventos e, sempre que possível, publicações de títulos próprios - livros, coletâneas e dossiês temáticos em periódicos -, que serão de autoria de integrantes do grupo, mas, também, de não integrantes que pesquisem sobre a Amazônia. O presente texto é representativo de uma dessas ações.

\section{Considerações finais, mas parciais, acerca de uma proposta em gênese}

Espera-se que as participações do GT em eventos, nas publicações, bem como na oferta de disciplinas nos Programas em que atuam os atuais treze participantes, minicursos eventuais e na orientação de projetos de especialização, mestrado e doutorado possam trazer relevante contribuição para a articulação e avanço da Pós-Graduação na área, na Amazônia brasileira.

Por sua vez, este número poderá ser ampliado à medida que novos componentes, que atuem em instituições que integram os estados e espaços que abarcam a Amazônia brasileira, queiram credenciar-se ao GT, desde que atendam aos critérios exigidos pelas normativas já instituídas e exigidas pela ANPOLL, assim como regras específicas que cabem diretamente ao Grupo de Trabalho, regras estas que estarão, em breve, disponíveis em um sítio que será criado. 
Além disso, é importante ressaltar que, conforme o Art. $8^{\circ}$ da Associação Nacional de Pós-Graduação de Pesquisa em Letras e Linguística, mencionado na Resolução Nº 01/1996, que dispõe sobre a criação e o funcionamento dos GTs, o GT apresentará o resultado parcial ou total de suas pesquisas ou atividades, seja nos congressos da ANPOLL, seja em reuniões científicas ou acadêmicas de reconhecida importância.

Reitera-se, uma vez mais, que a instituição deste GT pretende ser um meio de fortalecer a pesquisa na região amazônica, bem como mostrar que neste espaço amazônico já há uma significativa produção científica, que aspira, a partir de agora, ser implementada com novos resultados e produções, os quais objetivam ser acrescidos aos estudos realizados em outras regiões do país, para serem cotejados por pesquisadores ou para que possam servir de banco de dados para futuras pesquisas. Sendo assim, destacam-se, dentre as metas do GT, compartilhar e divulgar a produção científica desenvolvida aqui, com o propósito de cooperar com a pesquisa nacional na área e com os interessados nos estudos linguísticos realizados na Amazônia em instituições de ensino superior.

A ideia do GT, portanto, procurou e procura abarcar reflexões em torno de temáticas que focam o ensino, os falares, pensares e povos que aqui vivem experiências plurais, pois convivem em diversificados ambientes, temporalidades, espacialidades e culturas da/na Amazônia, sem, contudo, desvinculá-las do cenário nacional.

\section{Referências}

BARBOSA, S. M. A. D.; BEDRAN, P. F. Discurso e relações de poder na (re)construção da identidade profissional de professores de língua em uma comunidade de prática no ambiente digital. Horizontes de Linguística Aplicada, v. 15, p. 117-117, 2016.

BRASIL. Conselho da Associação Nacional de Pós-Graduação e Pesquisa em Letras e Linguística - ANPOLL. Resolução N $N^{o}$ 01/1996. João Pessoa, 30 de junho de 1996.

BEDRAN, P.; BARBOSA, S. Prática Colaborativa: concepções e reflexões a partir de uma perspectiva sociocultural. Domínios de Lingu@gem, v. 10, p. 89-120, 2016.

BEDRAN, P. F.; BARBOSA, S. M. A. D. Afinal, o que é uma comunidade de prática (CDP)? (re)pensando o(s) conceito(s)e a construção de uma CDP no e para o âmbito educacional de formação de professores de língua estrangeira. EntreLetras, v. 08, p. 35-56, 2017.

COSTA, L. C. S. PARFOR: realidade e desafios para a formação de professores pela Universidade Federal do Amazonas. Manaus, AM: EDUA, 2017. 
COTINGUIBA-PIMENTEL, M. L.; COTINGUIBA, G. C.; ANDRETTA, P. I. S. Bon Bagay: Glossário Português-Crioulo Haitiano = Bon Bagay? Glosè Kreyòl Ayisyen-Pòtigè. Porto Velho: Temática, 2018.

COTINGUIBA-PIMENTEL, M. L.; COTINGUIBA, G. C.; RIBEIRO, A. A. S. O crioulo haitiano e o seu reconhecimento político. Revista Universitas: Relações Internacionais, v. 14, p. 31-40, 2016.

COTINGUIBA-PIMENTEL, M. L.; SANTOS, A. P.; SANTOS, M. S. F.; ASSIS, W. L. S. Inserção sociocultural de haitianos em Porto Velho: o ensino e aprendizado da língua portuguesa. Revista de Estudos de Literatura, Cultura e Alteridade - Igarapé, v. 5, p. 43-53, 2015.

CRUZ-CARDOSO, M. L. de C. A realização das vogais médias pretônicas no Amazonas: um recorte baseado no Atlas Linguístico do Amazonas - ALAM. In: Gallaecia. Estudos de linguística portuguesa e galega. Universidade de Santiago de Compostela, 2017, p. 883-891.

CRUZ-CARDOSO, M. L. de C., MAIA, E. G., MARTINS, F. S. Reflexões sobre a variação do /S/ em coda silábica no falar amazonense: a hipótese de uma isófona. Web-Revista Sociodialeto. v. 7, n. 20, 2017.

ANJOS, Z. Fonologia e Gramática Katukina-Kanamari. Utrecht: Landelijke Onderzoekschool Taalwetenschap, 2011.

ANJOS, Z. Fonologia Katukina-Kanamari. Liames (Unicamp), v. 12, 2012, p. 123-156.

GAMA, A. S. M et. al. Inquérito de saúde em comunidades ribeirinhas do Amazonas, Brasil. Cadernos de Saúde Pública (CSP), v. 18, n. 02, p. 1-16, 2018.

HEIDTMANN NETO, H. G. C. A sensibilidade territorial das políticas públicas: Um estudo em comunidades ribeirinhas na Amazônia Legal. Tese de Doutorado. São Paulo, Escola de Administração de Empresas de São Paulo da Fundação Getúlio Vargas, 2008.

LIMA, A. S.; SANTOS, L. I. S. Formação de professores em pré-serviço: o fazer docente na oferta de língua inglesa para crianças. REVELLI-Revista de Educação, Língua e Literatura da UEG. Inhumas, v. 9, p. 37-57, 2017.

LIMA, J. L. A alternância entre as fricativas e africadas, a alternância de [ãw] e [õ] final e o gênero gramatical: marcas do português arcaico no falar cuiabano? In: PHILIPPSEN, N. I.; LIMA, J. L. (Org.). Diversidade e variação linguística em Mato Grosso. Cáceres, MT: Editora UNEMAT, 2018. p. 25-42.

MARTINS, S. A.; LIMA, A. dos S. A situação das línguas indígenas no município de Manaus. Revista Tellus, n. 35, janeiro/abril de 2018. Disponível em: http://www.tellus.ucdb.br/index.php/tellus/article/view/483 
MARTINS, S. A.; LIMA, A. dos S. Educação escolar indígena: um estudo sociolinguístico do Nheengatu na comunidade Pisasu do Rio Negro Amazonas. Revista Tellus, n. 33, maio/agosto de 2017. Disponível em: http://www.tellus.ucdb.br/index.php/tellus/article/view/443

MARTINS, S. A.; MARTINS, V. Particularidades no uso dos pronomes de segunda pessoa no falar manauara: um estudo no panorama da variação pronominal do português do Brasil. Interdisciplinary Journal of Portuguese Diaspora Studies. v. 3, n. 1, 2014. Disponível em: https://portuguese-diaspora-studies.com/index.php/ijpds/article/view/92

MORI, A. C.; CRUZ, M.; QUINTINO, W. P. Políticas linguísticas no curso de licenciatura intercultural da UNEMAT: manutenção e fortalecimento das línguas indígenas. Revista de Educação Pública, v. 26, p. 569-582, 2017.

OLIVEIRA, M. B. À guisa de uma explicação sociolinguística para a acentuada palatalização de /1/ em Itaituba-PA. Amazônica - Revista de Antropologia, n. 2, p. 220-248, 2010.

OLIVEIRA, M. B. et al. Palatalização de /1/: atuação de fatores sociais. Signum: Estudos de Linguagem, n. 19, v. 2, p. 239-259, dez. 2016.

OLIVEIRA, M. B. et al. Reinterpretando vazios dialetológicos no Norte do Brasil. Signum: Estudos de Linguagem, n. 21, v. 1, p. 12-31, dez. 2018.

OLIVEIRA, M. T.; LIMA, José Leonildo. Placas e anúncios publicitários com variação na flexão nominal de número. Web-Revista Sociodialeto, v. 4, p. 426-435, 2014.

PHILIPPSEN, Neusa Inês; LIMA, José Leonildo (Org.). Diversidade e variação linguística em Mato Grosso. Cáceres, MT: Editora UNEMAT, 2018.

QUEIXALÓS, F. \& ANJOS, Z. A Língua Katukína-Kanamarí. Liames (Unicamp), v. 6, 2006, p. 29-59.

QUINTINO, W. P. Aspectos da fonologia xavante e questões relacionadas: rinoglotofilia e nasalidade, 2012. Tese de Doutorado, Programa de Pós-Graduação em Linguística da Universidade Federal do Rio de Janeiro.

SANTOS, L. I. S. Unidades mato-grossenses do PROFLETRAS: abrangência, resultados e perspectivas. Letras \& Letras, v. 32, p. 16, 2016.

SANTOS, L. I. S.; SOBRINHO, G. R. (Org.). Multiletramentos: articulações para/no ensino da leitura e da escrita. v. 1. Cáceres, MT: Editora UNEMAT, 2015.

SILVEIRA, E. L.; AGUIAR, G. P. S.; COSTA, L. C. S. Alimentos (in)disciplinados: a beleza que (não) se põe na mesa. Caminhos em Linguística Aplicada, v. 17. n. 3, 2017. p. 484-508.

SILVEIRA, E. L.; SILVA, J. P. L. da; COSTA, L. C. S. Butler: leitora de Derrida: trilhando o caminho das desconstruções subversivas. Web-Revista Discursividade: Estudos Linguísticos, v. 19, 2017. 
SOUZA, E. C. de. Aspectos de uma gramática Shawã (Pano). Campinas, SP, 2012. Tese (doutorado) - Universidade Estadual de Campinas, Instituto de Estudos da Linguagem.

TOMÉ, C. L.; ROHDEN, J. B. O discurso do progresso e a educação na história de Sinop Mato Grosso: como é bom alargar fronteiras de nossa pátria!. História da Educação, v. 21, p. 312-334, 2017.

TOMÉ, C. L.; BISCARO, A. A. P.; RODRIGUES, D. A. A sustentabilidade no setor extrativista da floresta amazônica: percepções e conceitos. Gestão Ambiental. Belo Horizonte: Poisson, 2018, v. 2, p. 125-131.

TOMÉ, C. L. "Eu não sou professor, não": a presença do professor na cidade de Cláudia entre 1978 e 1988. Tese de Doutorado em Educação, Universidade Federal do Rio Grande do Sul, 2009. 